\section{GDC CHAIR MUST GO SAYS BRITISH DENTAL ASSOCIATION}

The British Dental Association (BDA) has called on the chair of the General Dental Council (GDC), Bill Moyes, to resign following a damning indictment of the regulator in a report published by the Professional Standards Authority (PSA).

The publication of the longawaited PSA report into GDC whistleblowing has revealed unacceptable organisational and personal failings at the top of the organisation.

The PSA report demonstrates not just historic failures, but an on-going crisis of governance and oversight at the GDC.

The overseer of all the healthcare regulators in the UK, the PSA, singles out the current Council chair for a litany of failures and 'inappropriate' decisions.
- The PSA said it was inappropriate of the chair to appoint the GDC's former Director of Governance to investigate his/her own manager

- The GDC prevented the PSA from accessing the information it needed to complete its enquiry.

All in all, the BDA believes this highly critical report paints a picture of a management team doing exactly what it wanted to do and a Council not holding it to account.

Commenting on the report, BDA chair Mick Armstrong said: 'The BDA has consistently argued that the GDC is out of control and unaccountable. Once again, we can see why.

'The chair doesn't understand dentistry and has failed to grasp that a fundamental prerequisite for good

\section{DENTISTS CAN HELP TURN THE TIDE ON ORAL CANCER}

The British Dental Association (BDA) has welcomed recognition from Ministers that dentists must be part of a joined-up response to the mounting cases of oral cancer.

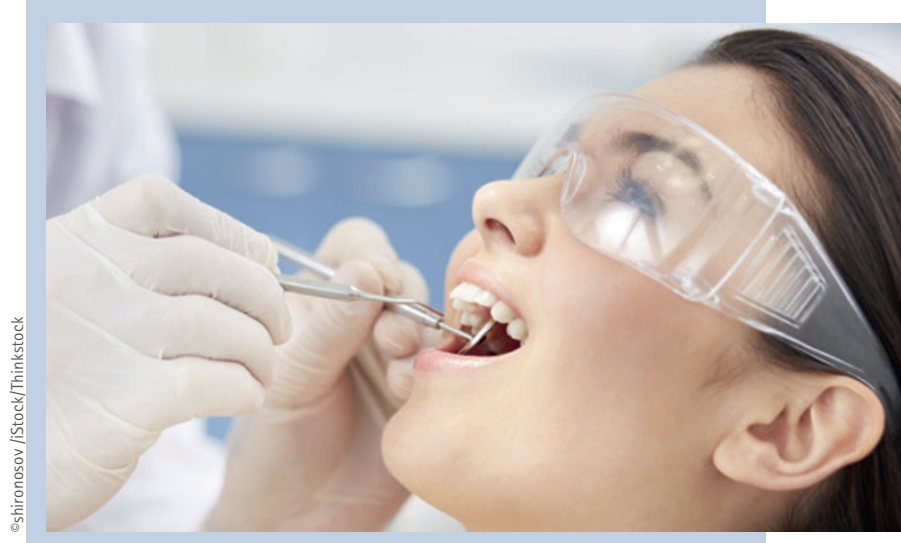

In a Westminster Hall debate on tobacco control strategy both government and opposition health ministers acknowledged the vital role dentists can play in early diagnosis of mouth cancer. Oral cancers currently kill more people in the UK than cervical and testicular cancers combined.

The BDA recently partnered with Cancer Research UK to launch a new toolkit designed to help dental health professionals when identifying and referring possible cases of oral cancer. Dentists and their teams are the only healthcare professionals who frequently see patients who have not yet noticed any symptoms, and so are in an excellent position to catch possible oral health problems early on, massively increasing potential chances of survival.

Mick Armstrong, Chair of the BDA, said: 'The spike in oral cancer cases shows precisely why we need real joined-up thinking across our health service. We are seeing a preventable disease on the rise, a killer that has a $90 \%$ survival rate - but only if it's spotted early.

'We've told MPs that dentists are uniquely placed to help turn the tide on oral cancer. When it comes to prevention and diagnosis we welcome acknowledgement - from both government and opposition - that our profession needs to be part of the emerging strategy.'

In the debate Jane Ellison, the Public Health Minister, said: 'We received welcome information today from the British Dental Association setting out how dentists can help with smoking reduction and the identification of oral cancer. We will consider that further as we develop the [new tobacco control] strategy. That is welcome and timely news.'

Andrew Gwynne, Shadow Public Health Minister, said: 'The general health implications of smoking are well known and documented, but mouth cancer often gets overlooked. Oral cancer kills more people in the United Kingdom than cervical and testicular cancers combined, yet there is still an alarming lack of public awareness about oral cancer.' 